\title{
LOCUTIONS IN MEDICAL DISCOURSE IN SOUTHWESTERN NIGERIA
}

\author{
Akin Odebunmi
}

\begin{abstract}
The paper examines the pragmatic roles that locutionary acts play in understanding the communication between doctors and patients in Southwestern Nigeria. Working within John Austin's locutionary acts, with restrictions to the lexical occurrences and lexical relationships observed in the discourse, it got data through tape recordings of doctor-patient conversations and interviews of both doctors and patients (and/or their relations).The findings revealed that two categories of locutions were engaged in hospital interactions, namely, locutions intended to be understood by non-professionals and locutions not intended to be understood by non-professionals. The paper observes that locutions in medical discourse in Southwestern Nigeria bring standard lexical choices and local linguistic initiatives of medical practitioners into a pragmatic union. It therefore concludes that the pragmatic engagement of these choices displays the tact the practitioners use in dealing with patients, and it recommends the need for the practitioners to master the locutions and their pragmatic adaptation for effective management of patients.
\end{abstract}

Keywords: Locutions, Pragmatic functions, Medical discourse, Southwestern Nigeria.

\section{Introduction}

A lot of studies have been carried out on medical discourse. These include studies in the traditions of discourse analysis and conversation analysis, e.g. Coulthand and Ashby (1976), Labov and Fanshel (1977), Mishler (1984), van Naerssen (1985), Drennan et al. (1991), Myerscough (1992), Wodak (1997), Chimombo and Roseberry (1998), Davidson (2001), Valero-Garces (2002), Briggs and Briggs (2003) and Wilce (2004). Works on medical discourse in Nigeria have concentrated on the register, linguistics and pragmatics of the discourse, for example Ogunbode (1991), Oloruntoba Oju (1996), Alabi (1996), Odebunmi (2003) and Adegbite and Odebunmi (2003). The studies on locutions in Nigeria have either cursorily treated the subject or merely sandwiched the locutions within a lot of other concerns.

This work is making a contribution in terms of studying the locutions of medical discourse in Nigeria, with emphasis on the vocabulary. It is specifically interested in identifying the locutions in the discourse and the pragmatic purpose they serve in communication. In actual fact, given the second language context in which the discourse is situated, the study will bring out the peculiar effects the context has on English usage 
in the hospital, and, thus, in a way examine how the standard medical linguistic forms co-exist with the local and contextual communicative initiatives to provide meaning in doctor-patient interactions in Nigeria.

Data were collected from doctors and patients in selected teaching, state government-owned and private hospitals in Southwestern Nigeria. Tape recordings of the interactions between the two groups were made and selected members of the groups were interviewed.

\section{Locutionary acts in communicative interactions}

Austin (1962), in his three-tier conception of linguistic communication as speech acts, sees performativity as consisting in locution, illocution and perlocution. Locution refers to making meaningful speech, "illocution is speech with a certain conventional force, and perlocution relates to speech with a certain non- conventional effect" (Halion 2003).

Locution or the locutionary act, which is our concern in this paper, has been conceived by Austin (1962) to cover phonetic act, phatic act and rhetic act. The performance of a phonetic act is indicated by the utterance of certain noises; that of phatic act goes with "uttering certain vocables or words i.e. noises of certain types, belonging to or as belonging to a certain grammar"; and that of rhetic act is marked by "using vocables with a certain more or less definite sense and reference" (ibid: 95). Obviously, the meaning-related units of locution, by Austin's conception, are phatic and rhetic acts. It is these two that will form our idea of locution in this paper, and they shall be guided strictly by a consideration for the context in which they are used (Austin 1962; Halion 2003). We shall therefore see locutions as vocabulary items that have certain senses and references when engaged in certain contexts by interactants.

What the speaker says, i.e. the locutionary act performed, could be referred to as the operational meaning of his/her utterance. This operational meaning is determined by (a) the sense (s) of the sentence uttered (b) the identity of the objects in the real world referred to by the speaker and (c) whether or not the speaker is speaking literally or figuratively (Fraser 1986: 32). These ideas should be complemented with insights from theories of lexical description. For meanings of words to be determined collocations have to be established. Terms such as nodes, collocates, spans, clusters and sets are of central importance here. Nodes are headwords of collocations, collocates are items that occur with a node, and spans "fix the extent of the stretches of language to be examined [each consisting] of the node and one lexical item on either side of it" (Berry 1977: 59). "A cluster is a list of the lexical items which can be collocated with a particular lexical item" (op.cit). We have a set when "a number of clusters are alike in that they can be conflated to form a set" (op. cit).

The task of determining the sense(s) of the sentence uttered is not an easy one, especially where the sentence is potentially ambiguous. This is because the intention of the speaker is largely often conjectured, and not accurately scientifically located. "On the assumption that in uttering a sentence the speaker always means one and only one sentence to be understood, the task of the hearer is to determine which one" (Fraser 1986: 32). The intended meaning of the speaker depends on the context of use i.e. Who is speaking? To whom is he/she speaking? What circumstances led to his/her utterance? 
When is he/she speaking? etc. Silverstein (2004: 632), working within the frame of lexical performance as a function of shared "knowledge about the world", asserts:

\begin{abstract}
Any time one uses a word or expression it indexes specific values or nodes within such knowledge schemata. Each such schemata of conceptual information is now made "relevant" to discursive interaction as a framework projected from it.
\end{abstract}

Silverstein (ibid: 638) argues that selecting appropriate lexical items and understanding them depend on shared cultural knowledge between interactants:

\begin{abstract}
Stereotypic meaning - cultural concepts - attached to words and expressions exist in a complex space between authorizing and authorized discursive engagements of the people in a population, and such stereotypes are not uniformly distributed across the population. Cultural knowledge is in part, intuitive knowledge of such biases of distribution, essentialized as kinds of people; such implicitly meta-cultural" knowledge is itself biased in distribution by the dynamics of the very processes of communication.
\end{abstract}

Reference relates to knowing the operational meaning of a word. The deixis, i.e. that of place, time and person, is very important in this context. A sizeable number of Hanks' works (1992, 1996, 2000,etc) have been concerned with deictic relations, and have shown how people refer to, describe and get themselves orientated in space. "Deixis belongs within the domain of pragmatics, because it directly concerns the relationship between the structure of languages and the contexts in which they are used" (Levinson 1983: 55). Deictics are special words engaged in pointing at things (cf. Gracia-Murga 1995; Mey 2000). They identify referents and relate such referents to the ground shared between the speaker and the hearer (Grundy 2000). The reference of indexicals shifts with utterances, depending on the current user, and their referents are partly determined by "extra-linguistic context (for instance, the time and location of the speaker and the speaker's intentions)" (Braun 2001: 21). According to Grundy (2000: 36) "because we use deictics to encode a relationship between persons, times, places and ourselves as speakers, we should expect individual uses to vary".

Deictics of time appear as temporal adverbials and tense items. They represent time as diurnal or calendrical units, and ultimately refer to roles of participants. Markers of time such as "today", "tomorrow", etc. indicate items that are relative to speakers (cf. Mey 2000). Tense is deictic in the sense that "nearly all sentences when uttered are deictically anchored to a context of utterance" (Levinson 1983: 77). In this regard, time deictics prove useful in management of time in utterances. Place deictics relate to "the encoding of spatial locations relative to the location of the participants in the speech event" (Levinson 1983: 62). Objects in spatial reference are either described/named or simply located. Either referencing is achieved through demonstratives and place adverbials. These items locate objects along the proximal or distal dimension. "Here", "this" and "these", for example, indicate proximity, while "there", "that" and "those" suggest distality. Person deixis "depends upon the notion of participant roles and upon their grammaticalization in particular languages" (Goddard 1998: 638). It is realized through personal pronouns in several contexts of use. The first person pronoun includes the speaker, the second person includes the addressee, but the 
third person excludes both the speaker and the addressee (cf. Levinson 1983). Smith (1989) notices that the first person pronoun can make multiple references to someone other than the speaker, a group of people, an imaginary person and an impersonal item. Mey (2000: 46) soundly argues that "personal pronouns are important in establishing the current point of view and as such are extremely sensitive to changes in that perspective". Emphasizing the place of context in deictic appreciation, Kataoka (2004: 410) contends that "the use of deixis in naturally occurring discourse has been regarded as the battleground of what is denotatively represented and connotatively presupposed/created..., and ... that the spatio-temporal deixis is inevitably meshed with interpersonal configurations created among discourse participants..."

Determining the locutionary act performed requires a consideration for literal as against figurative language usage. "Unless there is evidence to the contrary, the hearer should operate under the assumption that the speaker is speaking literally" (Frazer 1986: 33). However, studies on metaphor and recent advances in linguistic anthropology have shown that all discursive acts often tend to go in the direction of figurative usage (cf. Lakoff and Johnson 1980; Silverstein 2004).'The implicit conceptual metaphor ... is ... ritually literalized as "figuration'...." (Silverstein 2004: 636). Identities of interactants (and objects) are figurated, showing personality and social background. But, as Silverstein (op.cit) rightly points out, selecting appropriate words is constrained by exposure to the right experience. "The basis for using [the] verbal paraphernalia of such inhabitable figurations is the fact that, in essence, it takes one to know one" [ibid: 643].

\section{The terrain of medical discourse in (Southwestern) Nigeria}

English is sometimes used in bio-medical communication in Nigeria. The style of communication between doctors and patients could be generally classified as formal, consultative and informal. In most communities in Nigeria, especially in Southwestern Nigeria, English, a major official language of the country, is combined with indigenous language i.e., in this context, the unofficial language of the people. In the Southwest, Yoruba is used. Pidgin English is also sometimes used, mostly by the half-literate and non-Yoruba clients.

In many contexts where the attending medical practitioners and clients have competence in both Yoruba and English, they either choose one or code switch in an interaction. More often than not, however, between a medical practitioner and an elite client, English is preferred. The reverse occurs where the client is unable to speak English. In this case, if the attending practitioner can speak the client's indigenous language, both interact in it; if he/she cannot, then another practitioner, who can speak his/her language, may be invited or an interpreter may be used. On some occasions, nationals of other African countries; for example, Togo and Benin Republic, who understand no more than their indigenous languages and, many times, French, have to be communicated to through interpreters or gestures where the practitioner cannot speak any of the languages spoken by these clients. Sometimes, gestured communication is favoured in the hospitals when deaf persons come for medical attention. Of course, the medical practitioner is expected to be able to cope with this situation. 
In hospital interactions, the goal is to strike the transactional and interactional functions of language, together with the speech acts that accompany each function. Transaction captures the actual business of talk in the hospital, while interaction deals with the interpersonal features. In serving the transactional functions, the major business transacted in the hospitals between doctors and patients are diagnosis, prescription and treatment. Interactionally speaking, English, or any language intelligible to both the doctor and the client, is used in the hospital to establish and cement relationships, which may be casual, cordial or professional. Medical practitioners, together with other categories of workers, greet each other; they ask after their colleagues' families, they sometimes make jokes to kill time and boredom, etc. The same gesture is extended to patients. If the patient speaks or can speak English, he/she is greeted and ushered in in English; otherwise, an indigenous language, Pidgin English or any other code understandable to participants is used. Sometimes, for tactical professional reasons, the doctor asks after the patient's family and goes into some other issues of intimacy before the actual medical interview takes place, or, sometimes, as part of the actual medical interaction. Through these means, the doctor may gain information about the state of health of the client. This is when the doctor uses the interactional mode to achieve a transactional end.

It need be said, however that, the transactional or interactional role played by language in the hospital environment depends on the nature of interaction: the kind of ailment being tackled, the personalities of interactants and the kind of information sought in the encounter. The question posed by doctors, usually after the prefatory greeting, often demand information from the patient; for example: When did it start? What did you use? What do you suspect is the problem? Do you sleep well? Do you cough? . Where questions come from the direction of the patient to the doctor, queries, as in those from the doctor, are issued to be answered; e.g Can I survive this? What is the ailment?. Generally, patients see their encounters with doctors as serious ones where no room should be allowed for casual or relaxed talk. Yet, evidence is there to show that on a good number of occasions, exchanges border on the domestic, professional, religious, and other non-medical experiences of interactants. Sometimes, age dictates the path of medical consultative sessions. Many times in Nigerian hospitals, aged people are handled with more amenities and intimacy than younger people.

Adegbite (1991) observes that the interactive patterns in western/orthodox medicine appear to be the opposite of the practice in traditional medicine (now dubbed vernacular medicine), especially in the Yoruba community, where elaborate greetings and other forms of intimacy are dominant. Along this line, it can be argued that, given the aligning divinatory tenor of the traditional medicine, more intimate issues, which sometimes amount to exchanging experiences, teasing, joking, etc. are made to dot the encounter. The priest usually asks after a long list of relations, neighbours and, sometimes, acquaintances, especially where the client is a regular patron. The amenities sometimes extend to discussing the current season, economy, business life of the client, etc. Notwithstanding this level of intimacy, however, a lot of information regarding the condition of health of clients is exchanged, which means that it is not easy to quantify the transactional or interactional contents of either western or vernacular medicine. In fact, the trend in modern vernacular medical practice in Nigeria in recent times, as 
shown in the styles of practitioners like Akintunde Ayeni (www.doctorayeni.com) moves towards the clinical nature of Western medicine.

Above all, medical communication is situated in a socio-situational and institutional context. It touches on the intention of the parties in interaction, i.e. medical practitioners and patients, the circumstances around the necessitating speech event, i.e. the context, and the effect intended on the hearer.

\section{Analysis and findings}

Our findings revealed, given the pragmatics of hospital interactions, two categories of locutions; namely: locutions intended to be understood by non- professionals and locutions not intended to be understood by non-professionals. Each shall be taken in turn.

\subsection{Locutions intended to be understood by non-professionals}

Medical practitioners $(\mathrm{Mp})$ engage plain words in situations where they mean their communication to be understood by patients and or their relations (hence forth, Pt or Ptrel). By plain words is meant words that do not rigidly commit themselves to specific specializations, but that are freely drawn upon by people in several areas of life to express and describe their different experiences. These words have been tamed to serve some sort of sub-technical functions in medical practice.

In most cases, these words are used where Mps talk to Pts or Pt-rels about the latter's conditions of health, where they state treatment, indicate follow-ups and respond to Pts' complaints. Communication here is explicit and operates largely within Pt's lexical competence. This explicitness obviously indicates that Mps observe the Gricean maxim of manner, and strictly follows the medical prescription for MPs to use simple, well-known words (Harlen 1977).

When Mp relates with Pt on his/her condition, he/she considers the need to make him/her clearly understand what the state of him/her condition is, especially, given the fact that the actual experience of the condition is by $\mathrm{Pt}$; $\mathrm{Mp}$ only puts it in the right professional lexical frame to suit the convention of medical practice. The following interaction between an $\mathrm{Mp}(\mathrm{doc})$ and a Pt provides an example:

\section{Interaction I:}

Doc: Tell me, what happened?

Pt: I'm still single. I got pregnant and because I'm not, I mean, working and my partner too, we decided to abort the pregnancy.

Doc: How and where did you go for the termination?

Mp (doc)'s question prompts such choices as "pregnant", "abort" and "pregnant" from $\mathrm{Pt}$, who had undergone a criminal abortion procedure under an unlicensed practitioner. Pt's response here has been dubbed a requested account (Fisher and Groce 1990). 
Rather than repeat Pt's choices, Mp (doc) opts for the plain word 'termination", which captures the condition being described by $\mathrm{Pt}$, and which simultaneously implicitly speaks of the danger involved in the procedure, given the bad condition of $\mathrm{Pt}$ on presentation. This locution is confirmed towards the end of the interaction when Mp (doc) says:

You see, I only pray that the man has not caused you any serious, you know, I mean, eh, injury to, you know, your womb, because, you see with this fresh blood oozing out continuously.

The point is that Mp reaches for "termination" to make Pt see clearly the implications of her action and the prognosis of her condition.

Treatment-related locutions also attract plain words intended for Pts' understanding. It is part of Mps' style in Southwestern Nigeria to, in addition to indicating prescribed dosages of medicines on hospital prescription bags, orally inform $\mathrm{Pt}$ of the dosages. The locutions are therefore expected to draw on lexical resources that Pt can easily understand for effective administration of the medicines and to avoid ambiguities. The same locutionary act passes sometimes between Mps for clarity, especially where status differential such as doctor- nurse variables exist, and Mp (Doc) does not want to risk a lack of uptake. Sometimes, the locutionary items selected have the function of explicitly explaining treatment procedures and carrying Pt along in the process. The following example can clarify some of these points:

\section{Interaction 2:}

Patient: $\quad$ Doctor, will I be admitted? I want to be under medical care in the hospital. Money is not my problem.

Doctor: Just go and stay outside and relax. I will send you to the laboratory first before any treatment (To the orderly) take this card to the laboratory head; I have written some laboratory investigations that are to be carried out on the patient including 3'3'3' screening.

The choice of the plain word, "investigations" contrasts with that of the phrase "3'3'3' screening" which Mp (doc) does not want to unveil to Pt. Mp is about to commence treatment on Pt, and he wants to intimate him with the process to be followed. What is pragmatic about "investigations" is its tendency to give Pt the impression that $\mathrm{Mp}(\mathrm{doc})$ is interested in finding out ("investigation") the cause of her ailment. She has boastfully declared her financial capability. It will be revealed later in this paper that "3'3'3' screening" is the laboratory examination conducted for HIV/AIDS, itself an obvious reason for Mp's veil.

Complaining by $\mathrm{Pt}$ to $\mathrm{Mp}$ usually serves as an avenue for the two to exchange ideas and for Mp to establish the conditions of Pt and consequently diagnose his/her condition. This exchange obviously requires lexical selections whose meanings the participants can easily reach. Hence, plain words or popular medical jargon come readily into the scene. Also, in follow-ups, plain words are favoured to ensure that appointments are kept and independently administered medicines are ingested appropriately. The two interactions below would explain these points: 


\section{Interaction 3:}

Doctor: Hello madam, how is your health?

Patient: Doctor I am not well at all. I have been sick for more than three months, I am losing weight, and em diarrhea; I mean I have...

Doctor: (cuts in) Do you cough?

Patient: Yes, but not much

Doctor: Do you, I mean have this, you see, I mean skin rash at the onset of this illness?

Patient: Yes, but no more

Doctor: Any fever

Patient: Sometimes, some malaria

Doctor: Alright. Before anything we would have to do em series of em test for you.

\section{Interaction 4:}

Doctor: Mrs. X, your next appointment is September 3.

Patient: Thank you, doctor.

In Example 3, negotiation for meaning begins with Mp (doc) picking the word "health", a term obviously known to any speaker of English. Pt responds with the plain word "(not) well", an item, which together with "sick", establishes the reason for Pt being in the hospital and sets $\mathrm{Mp}$ (doc) on the search for the reason. With a flout of the Gricean quantity maxim using the plain word "weight" (loss) and the popularly distributed medical term "diarrhoea", Pt narrows down the scope of the earlier words i.e. "not well" and "sick". Mp (doc) thus comes up with a question specific to the narrow range, evoking his professional knowledge relating to the features "losing weight" and "diarrhea". "Cough", a word accessible to Pt, ventures to pin down Pt's ailment within Mp (doc)'s knowledge of a suspected condition. The same is done with the plain words "(skin) rash" and "onset", and the popular "fever", all of which yield appropriate requested and appended responses (Fisher and Groce 1990) from Pt. The interaction could perhaps have broken down if pragmatically irrelevant items such as "tussive" for "cough", "dermatological condition" for 'skin' rash" and "pyrexia" for "fever", effective only in Mp-Mp interactions, have been used by Mp (doc). Such selections are sometimes made by Mp (doc) in the hospitals sampled but, they are completely avoided during history taking sessions such as Interaction 3 demonstrates.

In Interaction 4, Mp (doc) selects the plain word "appointment", which is intensively expressed as "September 3", itself temporally locating Pt's next meeting with Mp (doc). Pt would probably have been confused if an item like "RTC September 3", a locally coined acronym "Return to Clinic", exclusively used in written communication in the hospital, has been selected.

\subsection{Locutions not intended to be understood by non-professionals}

Our findings reveal that a good number of the vocabulary items used in the hospitals are deliberately selected to edge Pt or Pt-rel. out of the communication. This edging out, using jargon, codes and slang, occurs during diagnosis, when certain unsavoury 
conditions of Pt's are being discussed, and when certain treatment procedures are judged not be meant for Pt to understand.

It is common in the hospitals for Mps to either switch from plain to jargonic communication, or to execute an interaction all the way using jargon, when Pt or Pt-rel is in a critical condition and MP sees the need to tactically keep some information from him or her. Usually, to do this, Mp observes the maxim of quality, but exploits those of quantity, relation and manner. It often comes in the garb of the Orwelian double speak. According to Lutz (1989: 5), "when a member of the group [a professional group] uses jargon to communicate with a person outside the group, and uses it knowing that the non-member does not understand such language, then there is doublespeak". An example of this use in our data follows:

\section{Interaction 5:}

Background: A girl of 17 in a senior secondary school class was brought to Hospital X, for medical attention, by the father who was a clerk in a local government council. The two doctors on duty were discussing after one had conducted an ultrasound investigation on the girl.

Doctor I: $\quad$ The ultrasonic scanning revealed twelve weeks cyesis

Doctor II: $\quad$ DRAMA

Father: $\quad$ She was since [sic] March 4.

Pt-rel misfired. Mp (docs) have set up confusion for Pt-rel by the choice of technical expressions like ultrasonic scanning (instead of the more familiar "ultra sound" or the popular "pregnancy test") and cyesis (instead of "pregnancy"). The father who conspicuously did not suspect his daughter carrying any pregnancy was caught in the Mps' craft, and misinterpreted "twelve weeks cyesis" as the duration of the sickness. It was revealed in a follow-up interview that though the actual truth was disclosed sometime after the last episode, the MPs having successfully gauged the father's reaction, that the lexical choices were made deliberately to avoid the father having sudden psychological and physical upset, given the young age of the daughter and the father's non-expectation of her pregnancy.

Generally, lexical relationships in the data display some interesting patterns. Synonymy is the most dynamically used in the interactions. It occurred both in $\mathrm{Mp}-\mathrm{Mp}$ and Mp-Pt communication. The isosemantic items selected were either strictly technical or fairly technical, irrespective of the persons in communication, depending on the exigencies of the context. When communication with $\mathrm{Pt}$, for example, the selections took two forms:

(i) Selecting the common fairly technical items

(ii) Selecting the uncommon strictly technical items.

When Mp (doc) selected a word like fever, infection or dysentery, it was largely done with the common background that Pt or Pt-rel. would understand, or, at least, have access to some of the meaning intended as in the first part of our analysis. An utterance like the following: You are feverish, if substituted with You are pyrexic would surely put Pt in the dark, despite the fact that the two words fever (ish) and pyrexia(ic) are 
synonymous. The other form, i.e. selecting the uncommon strictly technical items, was also sometimes employed in doctor/patient interaction. More often than, as our findings revealed, $\mathrm{Mp}$ (doc) sometimes decided to select items like pyrexic, plasmodiasis, septic and other technical items on some occasions to either confuse Pt or keep certain information concerning Pt from him or her. Many times, this occurred when the diagnosis was unfavourable, or when $\mathrm{Mp}$ (doc) judged the approach the most practically suitable as in Interaction 5.

There are times when MPs talk jargonically as a tactical measure to impress Pt about the procedure being carried out, so that his/her co-operation would be obtained. A good example of this discourse situation is presented below:

\section{Interaction 6:}

Background: Patient X, a referral from another hospital (a second year student of a Nigerian University) was brought in with respiratory distress. She was conscious and alert. She gave a history of difficulty in breathing of about three days' duration, which made her to present at the referral hospital about fifteen hours earlier. Despite the treatment given, the problem only abated for a while to recur in a more severe way. She was an asthmatic patient that had earlier been placed on drugs. She was seated in a wheel chair and pushed to the doctor's consulting room.

Doctor: (Eagerly waiting to receive the patient): please bring the patient in (to the nurse) Get me an ampoule of adrenaline. It is injection. It should be given now.

Patient: (Calming down after the injection had been given, but still with slight respiration distress) Doctor, Thank you sir; I hope I will survive this.

Doctor: Just calm down; it is well. The injection given now is a potent bronchidilator. So, worry less. I will also place you on admission so that I will be able to monitor the level of your response to the treatment.

Mp (doc)'s first choice of jargon, "ampoule of adrenaline" has no pragmatic value. It only serves as a spontaneous choice in the exigency of the context: Pt has to be rescued, and an order has to be given most accurately i.e. in the right professional parlance, to get the right object fetched. However, a pragmatic choice has to be made of "bronchidilator". Ordinarily, Pt, who has no knowledge of medicine, need not be told strictly technically what the "ampoule of adrenaline" does. It is sufficient to stop at "... It is well". What however, seems to practically spur the contextual choice of potent bronchidilator is the deep worry expressed by Pt: "I hope I will survive this". Mp (doc) sees the need to make Pt believe that his effort would provide the healing Pt needs. The high sounding term therefore, serves to make Pt realize that a lot of MP (doc)'s effort has gone into the procedure. He then backs this assurance up with the expressive, "so worry less". The tact of Mp (doc) yields the perlocutionary effect of sufficiently impressing Pt and giving her hope; hence, she responds: "I believe I will not stay too long on admission bed...."

Sometimes, medical codes and slang are also engaged to keep information from Pt. The codes in the data appear as a secret set of numbers or letters which are understood only by Mps, while slang appears as coinages from English and, sometimes, 
indigenous languages. Sometimes, the linguistic sources of the coinages are not known. For example, the code 333 is an arbitrary sequence of numbers chosen by a Nigerian hospital to refer to HIV or AIDS; the slang pack or its pidgin equivalent pirah means "die"; but poki poki, another slang meaning "retain the placenta" is not English; in fact, its source is not known.

In the interaction between Mp (doc) and Pt in Example 3, Mp says: "I have written some laboratory investigations that are to be carried out on the patient including 3'3'3' screening". The code 333 screening serves as a veil to prevent $\mathrm{H}(\mathrm{Pt})$ from knowing that he was to be tested for HIV/AIDS. The basis for this locution was supplied in an interview conducted with one of the doctors in the hospitals sampled:

Researcher: Please, do you in any way hide information regarding your client's condition from him or her?

Doctor: Yes and no. One of the rights of the client is a right to know; that is a right of full information about what is wrong with the patient. In fact, that is why the patient has come to the doctor. So, that is the "no" aspect of it. The "yes" aspect of it is, we hide some things in the early stages until it [sic] is confirmed, for instance if the patient has symptoms suggestive of AIDS or HIV infection and we are $80 \%$ sure based on what he has, we will hide if from him until we are $100 \%$ sure because like I've said earlier because of a risk of stigmatization.

This comment expressively confirms the locution in our example in Interaction 3. The doctor's reasons for the test are: Pt coughing, having diarrhoea, experiencing fever and developing skin rashes. These, following the doctor's comment above, constitute about $80 \%$ (conservative) evidence for the infection, but do not give the doctor the guarantee to go ahead and disclose it. Yet, this approach does not hold in all cases. In other social - neutral ailments like malarial fever, typhoid fever or even asthma, at any reasonable percentage, the diagnosis can be declared, while still awaiting results of laboratory tests. But given the societal attitude to HIV/AIDS, the doctor needs a scientific proof to pronounce the diagnosis.

According to the same doctor above, one of the mildest effects of disclosing terminal ailments to Pt or Pt-rel is the latter slipping into emotional outrage; others may be death (see Odebunmi 2003). Such effects are worse when laboratory proofs are not available, for the results may ultimately prove otherwise. It is against this background that 3'3'3' screening known only to Mp (doc) and Mp (nurse) has been selected by the latter.

More often than not, medical codes are selected to communicate unfavourable diagnoses to $\mathrm{Pt}$, when other non-medical professionals are available at the interaction. Sometimes, the ailment is already disclosed to Pt. A slightly different situation is where codes are used in the hospitals for security purposes. In one psychiatric hospital visited, a schizophrenic patient was seated beside a nurse directly opposite the attending doctor, flanked by his relations. Then, all of a sudden, the patient started gnashing his teeth, an index, for the attending doctor, of a process to a wild outrage. Then the doctor said quietly to the nurse, between his speech:

Here, psyche D. 
No one but the two professionals understood the communication, for none of the relations present showed any understanding. The doctor has only said that $\mathrm{Pt}$ is mentally deranged, and implicitly warned the nurse (i) to be on his guard so as not to be harmed by the mental patient and (ii) to make an urgent arrangement to prevent $\mathrm{Pt}$ from breaking loose. The locutionary act here rides on the spatial deixis "here", the lexical item "psyche" to symbolize the mental region, and the letter " $D$ " to abbreviate "deranged".

Slang, like codes, is used to prevent knowledge of unpleasant diagnoses and to protect patients from stigma, but not to serve any security function. In a private hospital, a nurse was attending to a young man who was in excruciating pains. The man's wife and his two-year-old daughter were in attendance. As the nurse was making efforts to check the man's vital signs, the doctor entered:

\section{Interaction 7:}

Doctor: Well done. Oh! What's wrong with this handsome man?

Nurse: Sir, he has a social disease.

The actual disease is a sexually transmitted disease, "gonorrhea". Yet, Mp (nurse) has chosen the slang "social disease" instead of "gonorrhea", working on the mutual contextual belief to avoid stigmatizing the patient before the wife, who obviously does not suspect the husband keeping extra marital affairs, and, not in the least, contacting gonorrhoea. Mp (Nurse)'s locution was inspired by the medical ethic that a patient's secret should be kept for as long as he or she wants it kept. Agbamuche (1982: 38-39) says in respect of this ethic:

\footnotetext{
The British Medical Association in 1949 put it Succinctly when it stated that a medical practitioner "should not disclose voluntarily, without the consent of the patient preferably written information which he has obtained in the course of his professional relationship with the patient". It includes information concerning criminal abortion, venereal disease, attempted suicide and concealed birth. Even the state has no right to demand such information except where notification is required by Statute such as in the case of infectious disease.
}

The discourse in Interaction 7 is an indication that the ethic is still in force in the medical circle. Little wonder we encountered in the hospitals such uses as "G.O." for "death", "c.a" for "cancer", "RV screening" for "HIV test", etc. In most cases, as our findings show, the patients' relations and, even many times, the patients themselves, were locked out of comprehension.

\section{Conclusion}

Our discussion has shown that two categories of locution feature in medical discourse in Southwestern Nigeria: Locutions intended to be understood by non-professionals and those not intended to be understood by them. We have claimed that each of these 
categories derives its contents from a robust interaction between the standards of the medical profession and the local contextual variables of conversational interactions. Each locution shows that the medical practitioner does not pick words randomly; rather, his/her intention, constrained by the physical context of interaction, takes a priority. Therefore, locutionary acts in medical practice in Southwestern Nigeria are performed with tact, and their uses require good mastery by medical professionals to manage patients effectively. The locutions derive from standard medical lexical sources and local linguistic initiatives of the practitioners. The standard lexical items are those used the same way across global settings in medical discourse, while the local or localized usages are those restricted to hospitals in Southwestern Nigeria. As noted, however, both forms of locution are adapted to the pragmatics of local interactions to achieve the meanings intended by the practitioners. The practitioners were observed, largely contrary to prescriptions of communication in bio-medical institutions in general, which require that they are blunt and precise to be largely diplomatic in communicating with co-practitioners and non-practitioners, given the socio-cultural peculiarities of the people in Southwestern Nigeria. When one of the doctors was asked if local lexical and discoursal innovations would not undermine the universality of medicine, he expressed a view that even though universal meanings might be hindered, yet the development made medicine more interesting.

It is difficult to sever the people from their culture and the sociological patterns they are accustomed to; so also is it difficult to isolate a language from interacting with another in its environment, and with the social-linguistic ways of life of the users. Our study of the locutions of medicine in Southwestern Nigeria has not only provided access to meanings intended of words in medical communication, it has also given insights into the degree of acclimatization of Western medicine to the environment. Future research can compare the locutionary behaviours of words in medicine in Southwestern Nigeria with those of its Western base. Such attempts can also compare the locutions of the nurses and those of the doctors with respect to consultation with patients.

\section{References}

Adegbite, A (1991) Some features of language use in Yoruba traditional medicine. Unpublished Ph.D. thesis. Ibadan: University of Ibadan.

Agbamuche, M.A. (1982) The doctor and the law. In E.S. Akpata (ed.), Medical Ethics. Lagos: Lagos University Press, pp. 39-42.

Ahearn, Laura M. (1998) A twisted rope binds my waist: Locating constraints on meaning in a Tij Sonfest. Journal of Linguistic Anthropology 8.1: 60-86.

Alabi, V. (1996) Parts of speech as communicative tools in medical texts. In Adegbija and Ofuya (eds.), English Language and Communication Skills for Medical, Engineering, Science, Technology and Agriculture Students. Ilorin: The English Language Outer Circle, pp. 202-212.

Ayeni, A. Yem-kem International Centre for Alternative Therapy. $\quad$ www.doctorayeni.com

Austin, J. (1962) How to Do Things With Words. Oxford: Clarendon Press. 
Berry, M. (1977) Introduction to systemic linguistics. London: BT Batsford Limited.

Braun, D. (2001) Indexicals. http://plato.stanford.edu/edu/entries/indexicals

Briggs, C. (1996) The meaning of nonsense, the poetics of embodiment, and the production of power in Warao healing. In C. Laderman and M. Roseman (eds.), The Performance of Healing. New York: Routledge, pp. 185-232.

Briggs, C., and C. Mantini-Briggs (2003) Stories in Time of Cholera: Racial Profiling During a Medical Nightmare. Berkeley: University of California Press.

Brown, G., and G. Yule (1983) Discourse Analysis. New York: Cambridge University Press.

Chimombo, M., and R. Roseberry (1998) The Power of Discourse: An Introduction to Discourse Analysis. New Jersey: Lawrence Eribaum Associates, Inc.

Collins, M. (1983) Communication in Health Care. Toronto: The C V Mosby Company.

Coupland, Justine, Nikolas Coupland, and J.D. Robinson (1992) "How are you?: Negotiating phatic communion. Language in Society 21.2: 207-230.

Cruse, D. (1986) Lexical Semantics. Cambridge: Cambridge University Press.

Crystal, D. (1976) The diagnosis of sociolinguistic problems in doctor-patient interaction. In D. Tanner (ed.), Language and Communication in General Practice. London: Hodder and Stoughton Limited.

Davidson, B. (2001) Questions in cross-linguistic medical encounters: The role of the hospital interpreter. Anthropological Quarterly 74.4: 170-178.

Drennan, G., A. Levett, and L. Swartz (1991) Hidden dimensions of power and resistance in the translation process: A South African study. Medical Psychiatry 15.3: 361-381.

Eggins, S., and J. Martin (1997) Genres and registers of discourse. In Teun A. Van Dijk (ed.), Discourse as Structure and Process. London: Sage publications, pp. 230-256.

Femi-Pearse, D. (1982) General ethical considerations and dilemmas in Nigeria. Medical Ethics. Lagos: Lagos University Press, pp. 61-74.

Fisher, S., and S. Groce (1990) Accounting practices in medical interviews. Language in Society 19: 225250 .

Finkler, K. (1994) Search healing and biomedicine compared. Medical Anthropology Quarterly 8.2: 178197.

Folarin, B. (1979) Context, register and language varieties: A proposed model for the discussion of varieties of English in Nigeria. In E. Ubahakwe (ed.), Varieties and Functions of English in Nigeria. Ibadan: African University Press, pp. 77-85.

Frazer, B. (1986) The domains of pragmatics. In J.C. Richards and W.S. (eds.), Language and Communication. London: Longman, pp. 2-57.

Frazer, B. (1990) Perspectives on politeness. Journal of Pragmatics 14.2: 219-236.

Ghadessy, M. (ed.) (1988) Registers of Written English. London: Pinter Publishers Limited. 
Goddard, C. (1998) Semantic Analysis. New York: Oxford University Press.

Gracia-Murga, F. (1995) Indexicals and descriptions.

http:www.ifs.csic.es/sorites/Issue_02/ite.5.ttm

Grundy, P. (2000) Doing Pragmatics. London: Oxford University Press.

Halion, K. (2003) Deconstruction and speech act theory: A defence of the distinction between normal and parasitic speech acts (Ph.D. Dissertation).

Halliday, M.A.K., and R. Hassan (1991) Language Context and Text: Aspects of Language in a SocialSemiotic Perspective. Oxford: Oxford University Press.

Hanks, W. (1992). The indexical ground of deictic reference. In A. Duranti and C. Goowin (eds) Rethinking context, language as an interactive phenomenon. Cambridge: Cambribge University Press, 209-246.

Hanks, W. (1996). Exorcism and description of participant roles. In M. Silverstein and G. Urba (eds.), Natural Histories and Discourse. Chicago: The University of Chicago Press, pp. 160- 220.

Hanks, W. (2000) [1993] The five grounds of memory. In Intertexts: Writings in Language, Utterance and Context. Lanham: Rowman and Littefield Publishers, Inc, pp. 197-217.

Hensyl, W.R. (1990) Stedman's Medical Dictionary. New York: Williams and Wilkins.

Holder, R.W. (1996) Oxford Dictionary of Euphemisms. Oxford: Oxford University Press.

Irvine, Judith (1998) Ideologies of honorific language. In B. Schieffelin, K. Woolard and P. Kroskrity (eds.), Language Ideologies: Practice and Theory. New York: Oxford University Press, pp. 51-67.

Kataoka, K. (2004) Co-construction of a mental map in spatial discourse: A case study of Japanese rock climbers use of deictic verbs of motion. Pragmatics 14.4: 409-438.

Lakoff, G., and M. Johnson (1980) Metaphors we Come to Live by. Chicago: University of Chicago Press.

Laurence, D.R., and P.N. Bennet (1982) Clinical pharmacology. Edinburgh: The English Language Book Society and Churchill Livingstone.

Leech, G. (1983) Principles of Pragmatics. New York: Longman.

Levinson, S. (1983) Pragmatics. Cambridge: Cambridge University Press.

Lutz, W. (1989) Notes on a definition of doublespeak. In W. Lutz (ed.), Beyond Nineteen Eighty-Four. Illinois: The National Council of Teachers of English.

Lyons, J. (1979) Semantics I. London: Cambridge University Press.

Lyons, J. (1981) Theoretical Linguistics. London: Cambridge University Press.

Mabayoje, O. (1982) Medical ethics in Nigeria: Its history, problems and appraisal. In E.S. Akpata (ed.), Medical ethics. Lagos: Lagos University Press, pp. 7-16.

Martin, E. (2000) Oxford Concise Medical Dictionary. Oxford: Oxford University Press.

Matthiessen, C. (1993) Register in the round: Diversity in a unified theory of register analysis. In Mohsen Ghadessy (ed.), Register analysis. London and New York: Pinter Publishers, pp. 221-292. 
Mey, J. (2001) Pragmatics: An Introduction. Oxford: Blackwell Publishers.

Mundy-Castle, A.C. (1982) Medical ethics: A psychologist's view. In E.S. Akpata (ed.), Medical ethics. Lagos: Lagos University Press, pp. 17-20.

Myerscough, P. (1992) Talking with Patients. Oxford: Oxford University Press.

Odebunmi, A (1996) Abbreviations and acronyms in MESTA texts. In Adegbija and Ofuya (eds.), English Language and Communication Skills. Ilorin: The English Language Outer Circle, pp. 248-261.

Odebunmi, A. (2001) The English word and meaning: An introductory text. Ogbomoso: Critical Sphere.

Odebunmi, A. (2002) The pragmatics of face acts in a Nigerian university administration. In Babatunde and Adeyanju (eds.), Language, Meaning and Society. Ilorin: Haytee, pp. 179-192.

Odebunmi, A. (2005) The context of hospital conversational interactions in Southwestern Nigeria. Journal of Pragmatics 1150.

Ogunbode, O. (1991) Effective communication in the medical sciences. In Adegbija (ed.), Effective Communication in Teaching and Learning: Basic Principles. Ilorin: University of Ilorin GNS Division, pp. 20-33.

Oloruntoba-Oju, T. (1996) Aspects of communication in the medical class. In Adegbija and Ofuya (eds.), English Language and Communication Skills. Ilorin: The English language outer circle, pp. 187-201.

Poyton, C. (1985) Language and Gender: Making the Difference. Geelong,Vic: Deakin.

Searle, J. (1969) Speech Acts: An Essay in the Philosoply of Language. Cambridge: Cambridge University Press.

Silverstein, M. (2004) Cultural concepts and the language-culture nexus. Current Anthropology 45.5: 621652.

Smith, Q. (1989) The multiple uses of indexicals.

http://www.qsmithwmu.com/the_multiple_uses_of_indexicals_quentin_smith.htm

Sokoya, G. (2000) Ethics and Legal Implications of Health Care: A Handbook for Nurses. Lagos: CSS Limited.

Stockwell, P. (2002) Sociolinguistics. London and New York: Routledge.

Tanner, B. (1976) Language and Communication in General Practice. London Hodder Stoughton.

Thomas, J. (1983) Cross-cultural pragmatic failure. Applied Linguistics 4.2: 90-112.

Thomas, J. (1995) Meaning in Interaction: An Introduction to Pragmatics. New York: Longman.

Van Dijk, T. (1976) Text and Context: Exploration into the Semantics and Pragmatics of Discourse. London: Longman.

Van Dijk, T. (1981) Studies in the Pragmatics of Discourse. The Hague: Mouton Publishers.

Van Dijk, T. (1997) Discourse as Social Interaction. London: Sage Publications. 
Wilce, J.M. (2004) Madness, fear, and control in Bangladesh: Clashing bodies of power/knowledge. Medical Anthropology Quarterly 18.3: (special issue on Illness and Illusions of Control) 357-375.

Woolard, Kathryn A. (2004) Code switching. In A. Duranti (ed.), Companion to Linguistic Anthropology. Malden: Blackwell.

Yule, G. (1996) Pragmatics. Oxford: Oxford University Press.

Yusuf, Y (1996) A speech act study of English and Yoruba proverbs on women. Unpublished Ph.D. Dissertation. University of Lagos. 